\title{
Tools for assessing damage in concrete affected by AAR coming from fine and coarse aggregates
}

\author{
Técnicas para a avaliação da deterioração proveniente \\ da reação álcali-agregado (RAA) gerada pela presença \\ de agregados reativos graúdos e miúdos
}

L. F. M. SANCHEZ a leandro.sanchez@uottawa.ca

B. FOURNIER b benoit.fournier@ggl.ulaval.ca

M. JOLIN c marc.jolin@gci.ulaval.ca

J. BASTIEN c josee.bastien@gci.ulaval.ca

D. MITCHELL。 denis.mitchell@mcgill.ca

\begin{abstract}
Over the last few years, comprehensive management programs for the diagnosis and prognosis of alkali-aggregate reaction (AAR) in aging concrete structures were developed in North America, based on a series of laboratory test procedures. Although promising, these lab-procedures presented several parameters whose impacts were not completely understood, which significantly reduced their applicability for the appraisal of deteriorated concrete structures in service. In this context, it has been suggested that two lab-tools, the Stiff ness Damage Test (SDT) and the Damage Rating Index (DRI) could reliably assess the condition of concrete affected by AAR. This paper presents the condition assessment of 25,35 and $45 \mathrm{MPa} A \mathrm{AR}$ affected concrete specimens incorporating fi ne and coarse reactive aggregates and presenting different distress degrees (i.e. expansion levels from 0.05 to $0.30 \%$ ) through the use of an innovative multi-level approach. Results show that both SDT and DRI are suitable for assessing damage in AAR affected concrete through their output parameters. Yet, they present a complementary character, which illustrates the need for a multi-level approach.
\end{abstract}

Keywords: stiff ness damage test, damage rating index, condition assessment, multi-level approach, alkali-aggregate reaction (AAR).

\section{Resumo}

Nos últimos anos, diversos programas de gestão para o diagnóstico e prognóstico da reação álcali-agregado (RAA) em estruturas de concreto foram desenvolvidos na América do Norte, com base em uma série de procedimentos experimentais em laboratório. Apesar de promissores, esses procedimentos apresentaram uma série de parâmetros cujo impacto não foi amplamente avaliado e discutido, o que reduziu significativamente a utilização destas técnicas na avaliação de estruturas de concreto deterioradas em serviço. Neste contexto, sugere-se que duas técnicas laboratoriais, o ensaio de Deterioração de Rigidez (SDT) assim como a avaliação microscópica do Índice de Deterioração (DRI) destacam-se como ensaios capazes de avaliar de maneira confiável e precisa o estado de deterioração do concreto afetado pela RAA. Este trabalho apresenta a utilização dos métodos descritos acima na avaliação da deterioração de differentes concretos (25, 35 e $45 \mathrm{MPa})$ afetados pela RAA, incorporando agregados reativos graúdos e miúdos e apresentando diferentes níveis de expansão $(0,05$ à $0,30 \%)$. Os resultados demonstram que tanto o SDT como o DRI são adequados para avaliar o nível de deterioração do concreto afetado pela RAA. Entretanto, estes apresentam um caráter complementar, o que ilustra a necessidade de uma abordagem "multinível" quando da utilização dos mesmos na avaliação de estruturas em serviço.

Palavras-chave: Deterioração de Rigidez (SDT), Índice de Deterioração (DRI), avaliação do estado de deterioração, avaliação multinível, reação álcali-agregado (RAA). 


\section{Introduction}

Alkali-silica reaction (ASR), one of the most common deleterious mechanisms identified in concrete structures worldwide, consists in a chemical reaction between "unstable" silica mineral forms (i.e. minerals that are susceptible for presenting dissolution under alkaline environments) within the aggregate materials and the alkali hydroxides $(\mathrm{Na}, \mathrm{K}-\mathrm{OH})$ dissolved in the concrete pore solution. It generates a secondary alkali-silica gel that induces expansive pressures within the reacting aggregate material(s) and the adjacent cement paste upon moisture uptake from its surrounding environment, thus causing microcracking, reduction of material's properties (mechanical/durability) and, in some cases, functionality in the affected structure [1].

Over the years, several approaches and recommendations, including a comprehensive variety of laboratory tests, have been developed worldwide to assess the potential alkali reactivity of concrete aggregates and the effectiveness of preventive measures (e.g. control of the concrete alkali content, use of supplementary cementitious materials, etc.) before their use in the field. Despite some issues with some of these test procedures, the majority of experts agree that, in general, it is now possible to construct concrete infrastructures with minimum or calculated risk of ASR. However, there is currently no consensus about the most efficient method(s) (surface treatments for moisture control, chemical treatments, strengthening, stress relief (slot cutting), etc.) that should be implemented, and when, for the rehabilitation of concrete structures/structural elements suffering from ASR.

In this context, one of the biggest challenges in dealing with ASR damaged aging concrete structures is to establish the correlation between ASR distress "signatures" (i.e. ASR distress illustrated in
Figure 1) and the loss/reductions in mechanical properties, physical integrity, durability and performance of the affected material, as well as their structural implications. Recent studies dealing with the evaluation of the mechanical performance of aging concrete suggest that both the Stiffness Damage Test (SDT) and the Damage Rating Index (DRI) can provide a diagnostic evaluation of the "damage degree" of concrete affected by ASR [2-4].

\subsection{Stiffness Damage Test (SDT)}

In the early 1990's, Crisp and co-workers proposed to use the SDT to quantify the degree of distress in concrete due to ASR [5, 6]. The test method was actually developed by Walsh [7] who observed a good correlation between the crack density and the cycles of loading/unloading (stress/strain relationship) of rock specimens. Crouch [8], following those results, proposed a new test procedure (Stiffness Damage Test - SDT) based on cyclic compression loading of concrete specimens (cylinders or cores) (Figure 2). A review on the SDT development as a diagnostic tool for assessing ASR affected concrete is presented in [2].

Sanchez et al. [2, 3] actually pursued the work of Smaoui and coworkers [9], by applying the SDT procedure to either specimens cast in the laboratory, presenting different mix-designs $(25,35$ and $45 \mathrm{MPa}$ ) and incorporating a wide range of reactive aggregates (i.e. coarse vs. fine reactive aggregates, $\neq$ lithotypes, etc.), or concrete cores extracted from an extremely damaged concrete overpass in Quebec City (Canada). The goal of those studies was to verify the influence of the test loading level and of several input parameters (concrete environment, humidity, specimen size, etc.) on the output test analyses. Likewise, the evaluation of the output test responses against the expansion levels of the affected
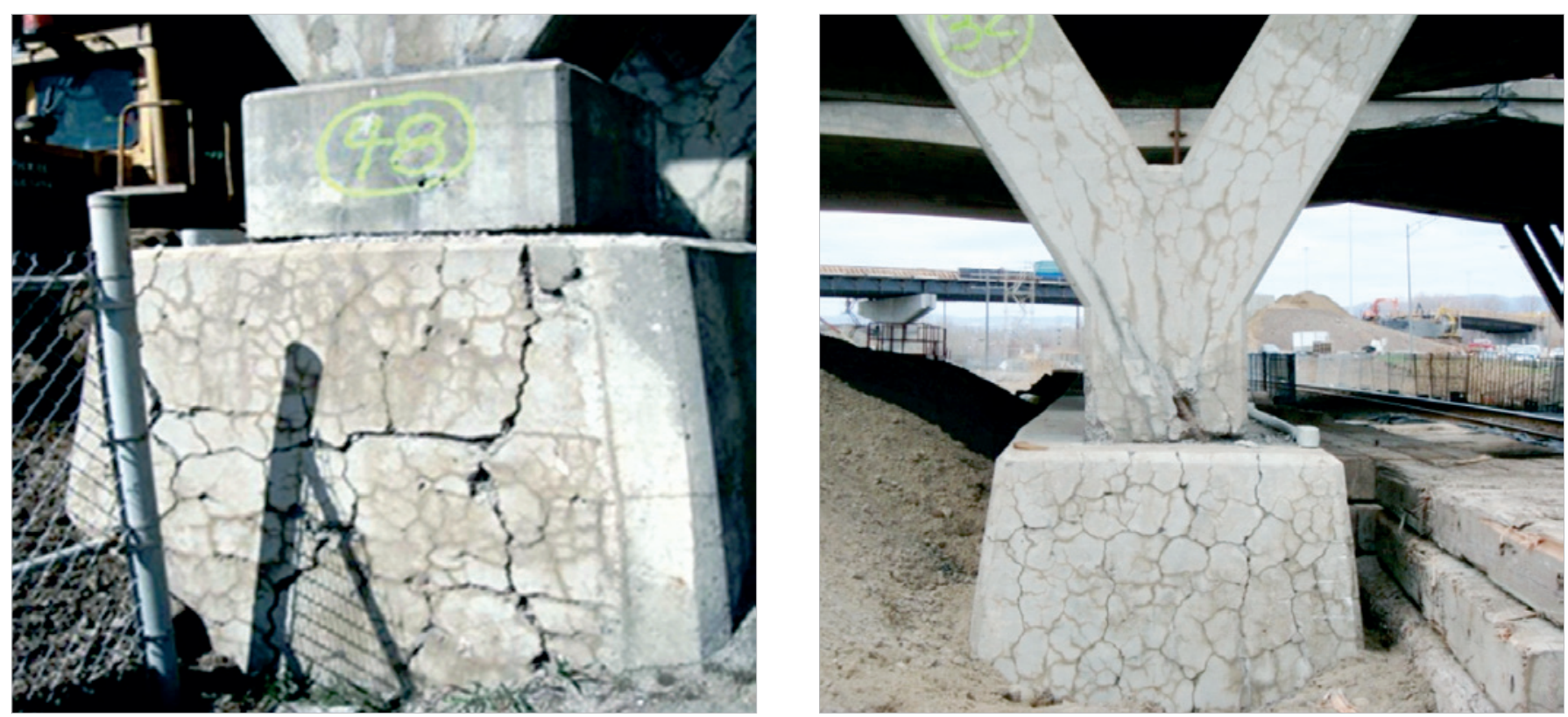

\section{Figure 1}

ASR distress signatures found on both the foundation blocks and columns of the Robert-Bourassa/Charest overpass - Quebec City, Canada 

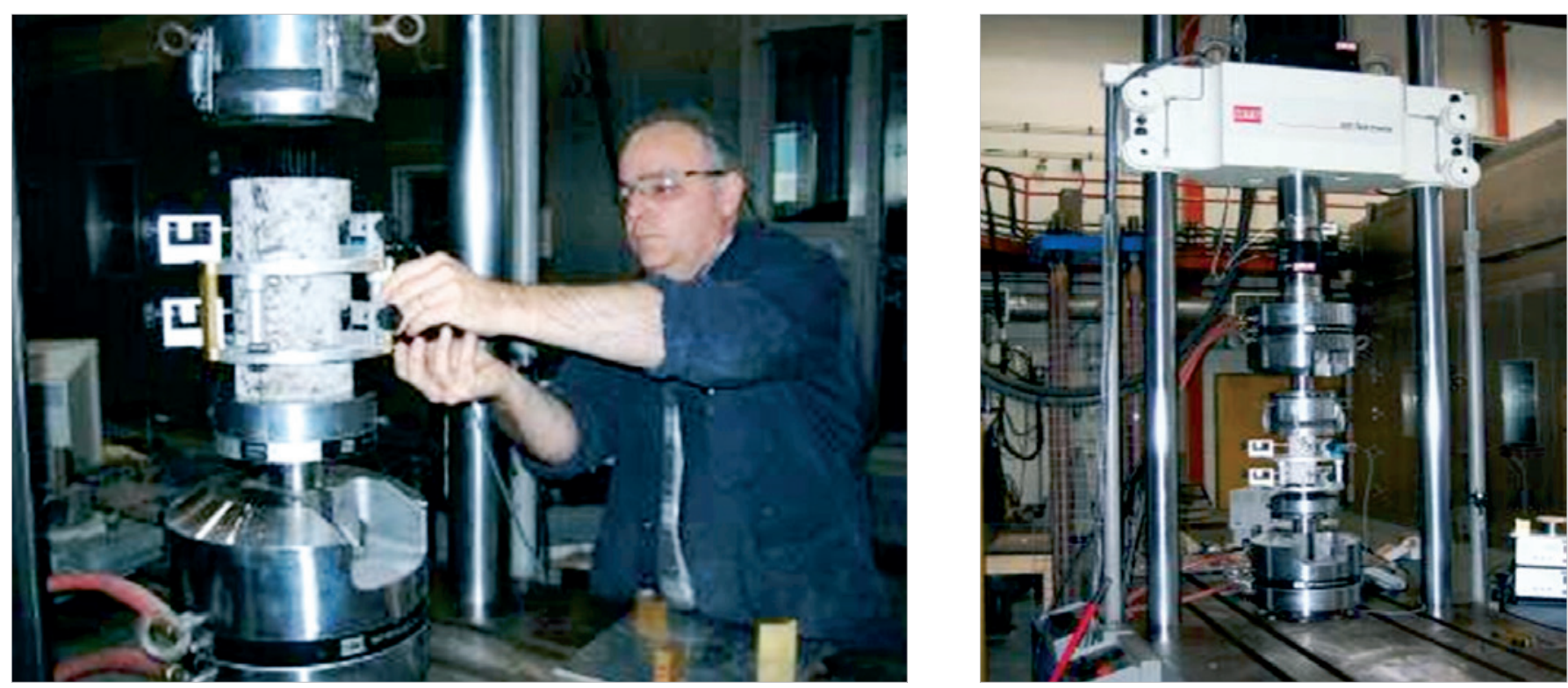

\section{Figure 2}

Set-up used for the stiffness damage test

specimens was performed. Based on the above studies, the authors presented the following main conclusions: 1) the SDT should be carried out with a percentage of the concrete strength instead of using a fixed load [2] (as originally proposed by [5, 6 and 9]); 2) the use of $40 \%$ of the design concrete strength seems to be the best approach for distinguishing damaged concrete specimens with regard to their expansion levels [2]; 3) the use of percentages up to $40 \%$ of the design concrete strength enables the use of the same specimen for supplementary analyses, such as compressive or tensile strength, since the test seems to keep its "non-destructive" character up to that point [2]; 4) the output parameters, such as the hysteresis area (HA) and the plastic deformation (PD) over the five cycles, as well as the modulus of elasticity (ME) (as an average value of the second and third cycles), seem to be the most diagnostic output results of the test;

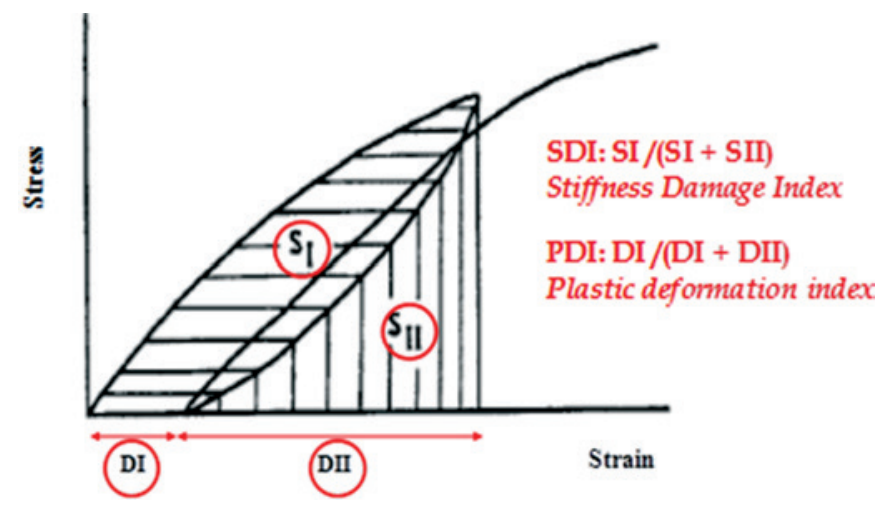

\section{Figure 3}

Determination of the Stiffness Damage Index (SDI) and Plastic Deformation Index (PDI) based on the output from the Stiffness Damage Test (SDT)
5) the use of indices (Stiffness Damage Index - SDI and Plastic Deformation Index - PDI) instead of absolute HA or PD values, which take into account the ratio "dissipated energy/total energy" implemented in the system, better represents the real "damage" of the affected materials (Figure 3). Actually, this approach decreases the impact of a poor selection of maximum loading level for stiffness damage testing and provides a better understanding of ASR evolution as a function of its expansion [10] and finally; 5) several input parameters, such as the concrete's cure history, the sample's geometry and size, and the sample's location within the structural member, seem to strongly influence the output analyses of the SDT [3].

\subsection{Damage rating index (DRI)}

The DRI is a microscopic analysis performed with the use of a stereomicroscope (about 15-16x magnification, Figure 4A) where damage features, generally associated with ASR, are counted through a $1 \mathrm{~cm}^{2}$ grid drawn on the surface of a polished concrete section (Figure 4B). The number of counts corresponding to each type of petrographic features (Figure $4 \mathrm{C}$ ) is then multiplied by weighing factors, whose purpose is to balance their relative importance towards the mechanism of distress (for instance ASR) (Figure 4D) [4]. It is important to mention that the factors used in the method were chosen on a logical basis, but relatively arbitrarily [11]. Ideally, a surface of at least $200 \mathrm{~cm}^{2}$ should be used for DRI analysis, and it may be greater in the case of mass concrete incorporating larger size aggregate particles. However, for comparative purposes, the final DRI value is normalized to a 100 $\mathrm{cm}^{2}$ area [11-13].

Villeneuve et al. [11] recently indicated that the variability between different operators performing the DRI could be significantly reduced by improving the definition/description of the different damage features, modifying some weighing factors, as well as 
by appropriate training of the petrographers using reference sections. Moreover, the authors proposed to use identical factors for the two categories of opened cracks in the aggregate particles (factor of 2) or cracks in the cement paste (factor of 3), with or without reaction products; this was done to reduce the variability associated to the difficulty in positively recognizing the presence of reaction products in cracks of the polished sections (Figure $4 \mathrm{C}$ ). Consequently, the two types of cracks could be grouped together having the same weighing factors if one considers that a crack is an indication of damage, either with or without reaction products. Also, larger weighing factors were selected for cracks in the cement paste, compared to that in the aggregate particles (i.e. factor of 3 vs. 2), to indicate a relatively greater importance regarding the durability of the affected concrete element. Finally, it was found that eliminating the counts of the number of voids with reaction products in the cement paste and the reaction rims from the calculation of the DRI values also contributes at reducing the variability between the operators and are not really direct indications of "damage" in concrete.

Since the process of damage generation varies through the type/ nature of reactive aggregate used (fine vs. coarse aggregate, lithotype, etc.), the DRI should ideally assess the nature and degree of distress features and correlate them with either the expansion attained by the distressed concrete or, ideally, with losses in mechanical properties [11-13]. Such information is, however, currently very limited.

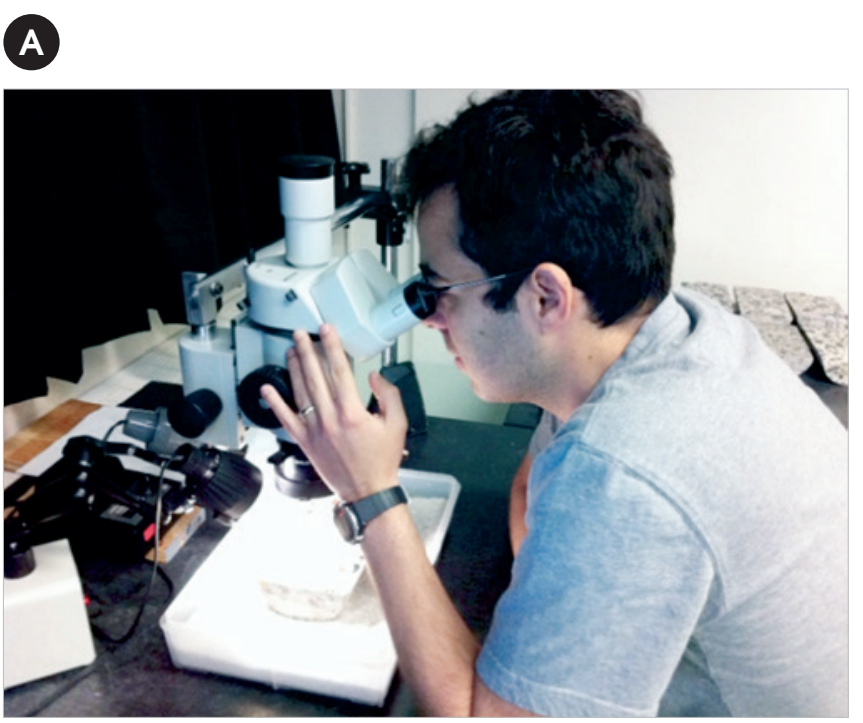

B

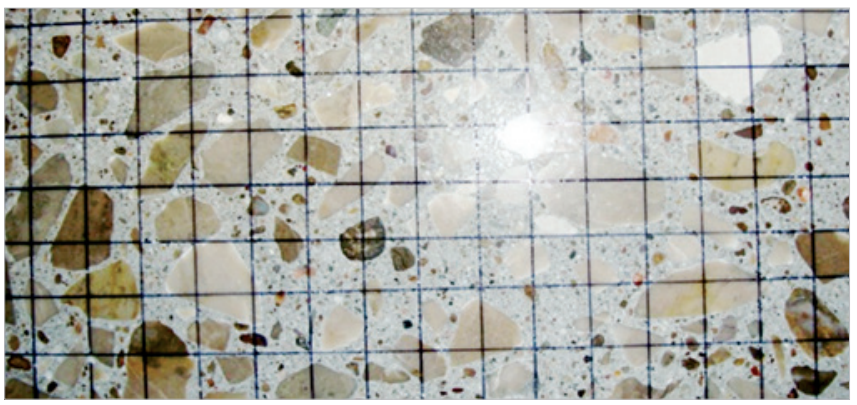

D

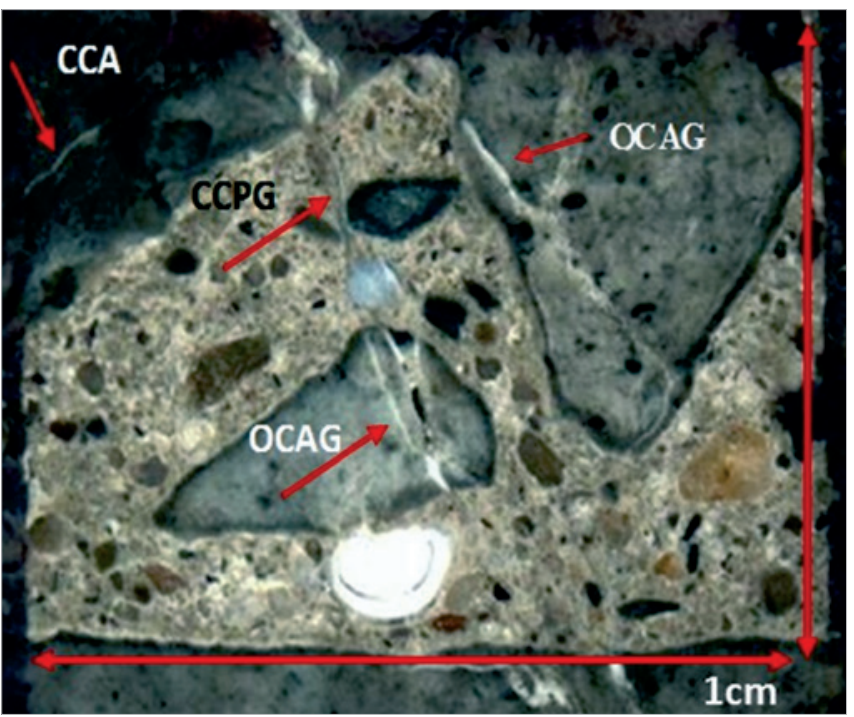

\section{Figure 4}

A) DRI stereomicroscope; B) $1 \mathrm{~cm}^{2}$ grid drawn on a polished concrete specimen;C) DRI weighing factors proposed as by (11); D) $\neq$ petrographic features to be noted through a DRI evaluation (4) 


\subsection{Scope of the work}

This paper discusses the use of the SDT and DRI for quantifying and understanding damage in concrete due to ASR, when the reaction is generated either in the coarse or in the fine aggregate. In order to best achieve this objective, extensive testing was performed on (well-controlled) laboratory-made and cured concrete specimens of different mix designs (25, 35 and $45 \mathrm{MPa})$ and incorporating coarse or fine reactive aggregates.

\section{Materials and experimental program}

\subsection{Materials and mixture proportions}

Three types of non-air entrained concrete mixtures (25 MPa, 35 $\mathrm{MPa}$ and $45 \mathrm{MPa}$ mix design strengths) and two highly-reactive aggregates (New Mexico gravel-NM and Texas sand-Tx) were selected for the study. The coarse aggregates ranged from 5 to $20 \mathrm{~mm}$ in size. Non-reactive fine and coarse aggregates (Lav sand in the case of NM mixtures and HP coarse aggregate for Tx mixes) were used in combination with the above reactive aggregate materials for concrete manufacturing. Table 1 gives the detailed concrete mixture proportions. After casting, the specimens were placed for $24 \mathrm{~h}$ in the moist curing room, and then they were demolded and left in this room for further $24 \mathrm{~h}$. Small holes, $5 \mathrm{~mm}$ in diameter by $15 \mathrm{~mm}$ long, were drilled in both ends of each test cylinders and stainless steel gauge studs were glued in place, with fast-setting cement slurry, for longitudinal expansion measurements. After completion of the first 48 $\mathrm{h}$ at $23^{\circ} \mathrm{C}$ and $100 \%$ R.H., the " 0 " length reading was performed and the specimens were placed in sealed plastic $(22 \mathrm{~L})$ containers lined with damp cloth (4 cylinders per bucket). All buckets were then stored at $38^{\circ} \mathrm{C}$ and $100 \%$ R.H., and all the test cylinders were monitored regularly for length variations. Moreover, as per ASTM C 1293, all containers were cooled to $23^{\circ} \mathrm{C}$ for 16 $\pm 4 \mathrm{~h}$ prior to periodic axial expansion measurements. Then, test cylinders were removed from the high-temperature storage conditions for SDT and DRI testing when they reached the expansion levels chosen for this research, i.e. $0.05 \% \pm 0.01 \%, 0.12 \%$ $\pm 0.01 \%, 0.20 \% \pm 0.01 \%$ and $0.30 \% \pm 0.01 \%$.

Once the above expansion levels were reached, the specimens were wrapped in plastic films and stored at $12^{\circ} \mathrm{C}$ until testing (be- cause of testing capacity issues). Prior to testing, both ends of each cylinder were carefully mechanically ground to avoid any interference from the stainless steel gauge studs used for expansion measurements. Also, even though they were wrapped in plastic film prior to testing, the specimens were restored for $48 \mathrm{~h}$ in the moist curing room, protected from running water, before stiffness damage testing, in order to allow appropriate saturation of the test specimens, following the procedure proposed for concrete cores extracted from real concrete structures (CSA A23.2-14C) [3].

\subsection{Methods for assessment and analysis}

\subsubsection{Stiffness Damage Test (SDT)}

Test cylinders were subjected to five cycles of loading/unloading at a controlled loading rate of $0.10 \mathrm{MPa} / \mathrm{s}$. All the specimens were tested at a strength level corresponding to $40 \%$ of the 28 -day concrete mix design strength, according to [2]. The results presented in this paper correspond to the average values obtained on three affected specimens at a given expansion level.

\subsubsection{Damage Rating Index (DRI)}

The DRI was performed on slabs cut and polished from specimens affected by the three distress mechanisms described before, and for all expansion levels selected for this work. Counts of cracking in the aggregate particles were made in particles down to $1 \mathrm{~mm}$ in size, instead of $2 \mathrm{~mm}$ normally used in the original method [4]. The latest weighing factors proposed by Villeneuve et al. [11] were used for the calculation of the DRI output values (Figure 4C).

\section{Results}

\subsection{Stiffness Damage Test (SDT)}

Figure 5 presents the SDT results in terms of SDI and PDI indices against the expansion levels of all the specimens used in this work. Looking at the SDI values (Figures $5 \mathrm{~A}$ ), one observes that this index may distinguish quite well the different expansion levels (or different amounts of internal cracking) for all the concrete mixtures, aggregates and strengths. In general, there is either a concave or a linear trend (depending on the concrete strength) of this variable

\section{Table 1}

Concrete mix designs used in the study

\begin{tabular}{|c|c|c|c|c|c|c|}
\hline \multirow{2}{*}{ Ingredients } & \multicolumn{2}{|c|}{$25 \mathrm{MPa}$ - materials $\left(\mathrm{kg} / \mathrm{m}^{3}\right) 1$} & \multicolumn{2}{|c|}{$35 \mathrm{MPa}$ - materials $\left(\mathrm{kg} / \mathrm{m}^{3}\right)$} & \multicolumn{2}{|c|}{$45 \mathrm{MPa}$ - materials $\left(\mathrm{kg} / \mathrm{m}^{3}\right)$} \\
\hline & Texas sand & NM gravel & Texas sand & NM gravel & Texas sand & NM gravel \\
\hline Cement & $314(101)$ & $314(101)$ & $370(118)$ & $370(118)$ & $424(136)$ & $424(136)$ \\
\hline Sand & $790(304)$ & $714(264)$ & $790(304)$ & $714(264)$ & $790(304)$ & $714(264)$ \\
\hline $\begin{array}{c}\text { Coarse } \\
\text { aggregate }\end{array}$ & 1029 (384) & $1073(424)$ & 1029 (384) & $1073(424)$ & $1029(384)$ & 1073 (424) \\
\hline Water & $192(192)$ & $192(192)$ & 174 (174) & 174 (174) & 157 (157) & 157 (157) \\
\hline
\end{tabular}


against the expansion level of affected specimens, ranging from about 0.08 for sound concretes up to 0.30 for $0.30 \%$ of expansion.

\subsection{Damage Rating Index (DRI)}

The detailed results of the DRI determinations, i.e. in terms of the relative importance of each of the various petrographic features of deterioration, are illustrated in Figure 6. At first glance, the following general trends can be observed from the graphs: 1) a commonly found feature of "deterioration" in all polished sections corresponds to Closed cracks within the aggregate particles (CCA - blue charts). In the case of Tx mixtures, this distress feature type is even more apparent; 2) a progressive increase in the number of cracking within both the aggregate particles (OCA, OCAG - red and green charts) and the cement paste, with and without gel (CCP, CCPG - orange and light blue charts) is found with increasing expansion of the test specimens; 3 ) the DRI values correlate well with the expansion levels measured for all the mixtures and aggregates selected for the study; 4) an interesting and different behavior could be noticed for the $45 \mathrm{MPa}$ concrete mixtures compared to both 25 and $35 \mathrm{MPa}$ mixes. Higher DRI numbers were found at low expansion levels, yet they remained stable up to $0.12 \%$, while increasing almost linearly and similarly to the other mixtures from about $0.12 \%$ up to the highest expansion levels tested in this study $(0.30 \%) ; 5)$ the DRI values seem to be not affected by the deleterious expansion process whether it originates from the fine (Tx) or the coarse (NM) aggregate and; 6 ) the data indicate that a certain degree of damage already exists in the test specimens (DRI ranging between 100 and 140, from some cracking in the aggregate particles and in the cement paste) for concrete specimens showing no significant expansion level (35 MPa mixtures).

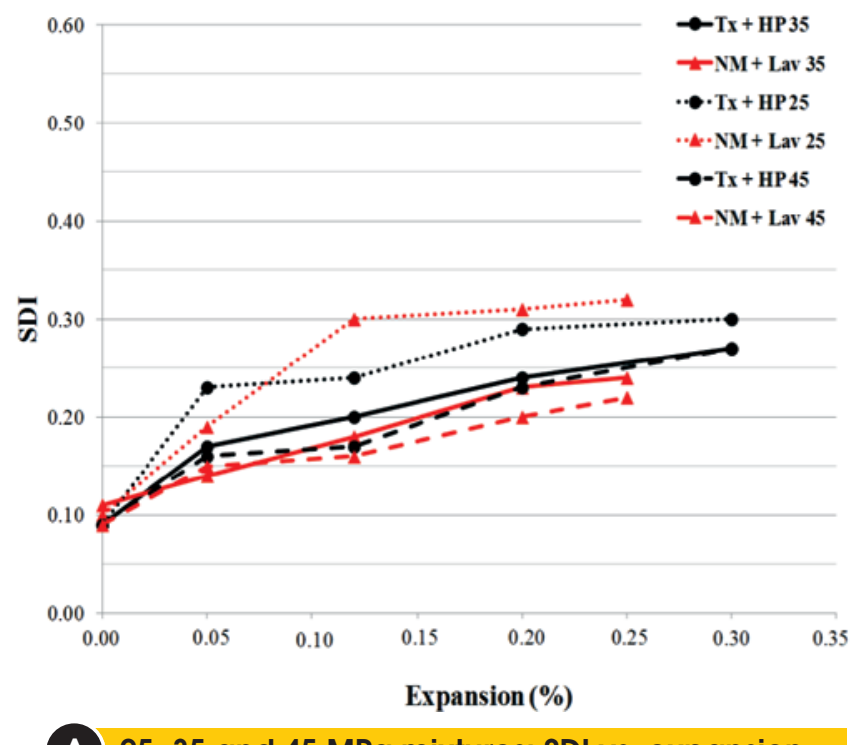

25, 35 and 45 MPa mixtures: SDI vs. expansion

\section{Discussion}

\subsection{SDT damage assessment}

According to [2, 3], the SDT, through its output parameters, is able to measure the progress of inner distress (i.e. cracking extent) as a function of expansion in concrete damaged due to ASR. Moreover, Sanchez [10] found that the use of the SDI and PDI indices, which take into account the ratio "dissipated energy/total energy" and "plastic deformation/total deformation" implemented in the system, respectively, would both better represent the real "damage" of the affected materials and also decrease the impact of a poor selection of maximum loading level for the test. The data presented in Figure 5 clearly illustrates that both the SDI and PDI were able to distinguish the progress of damage as a function of expansion when the distress is induced either by the fine (i.e. Tx mixtures) or coarse (i.e. NM mixes) aggregate particles.

The indices above showed to present a linear or concave trend against the expansion attained by the distressed samples. Therefore, this phenomenon could partially explain the concave trend of the SDT results. Moreover, another important point that should be considered regarding the curve's shape is the presence of gel in ASR systems. Since it is considered that the gel may migrate through the cracks with the progress of expansion [14], this phenomenon might likely difficult the "cracks closure" over stiffness damage testing (i.e. compression cycles), thus leading to lower SDI and PDI values towards higher expansion levels.

\subsection{DRI damage assessment}

According to [4], the DRI is able to evaluate either the distress characteristics or the distress development (i.e. expansion level)

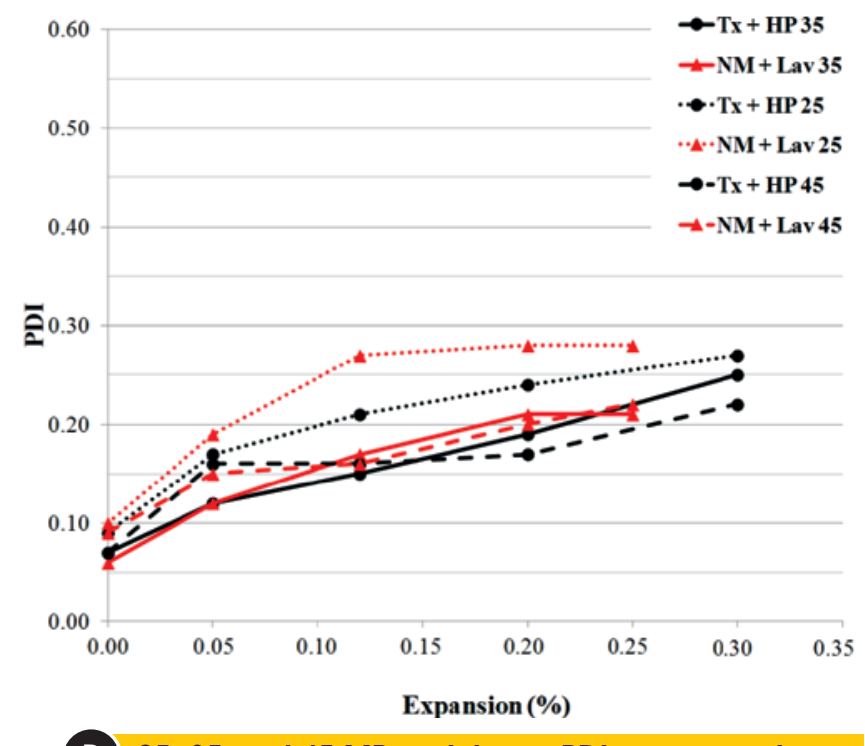

B 25, 35 and 45 MPa mixtures: PDI vs. expansion

\section{Figure 5}

Stiffness Damage Test results in terms of indices for the 25, 35 and 45 MPa mixtures: A) Stiffness Damage Index (SDI) and; B) Plastic Deformation Index (PDI) 


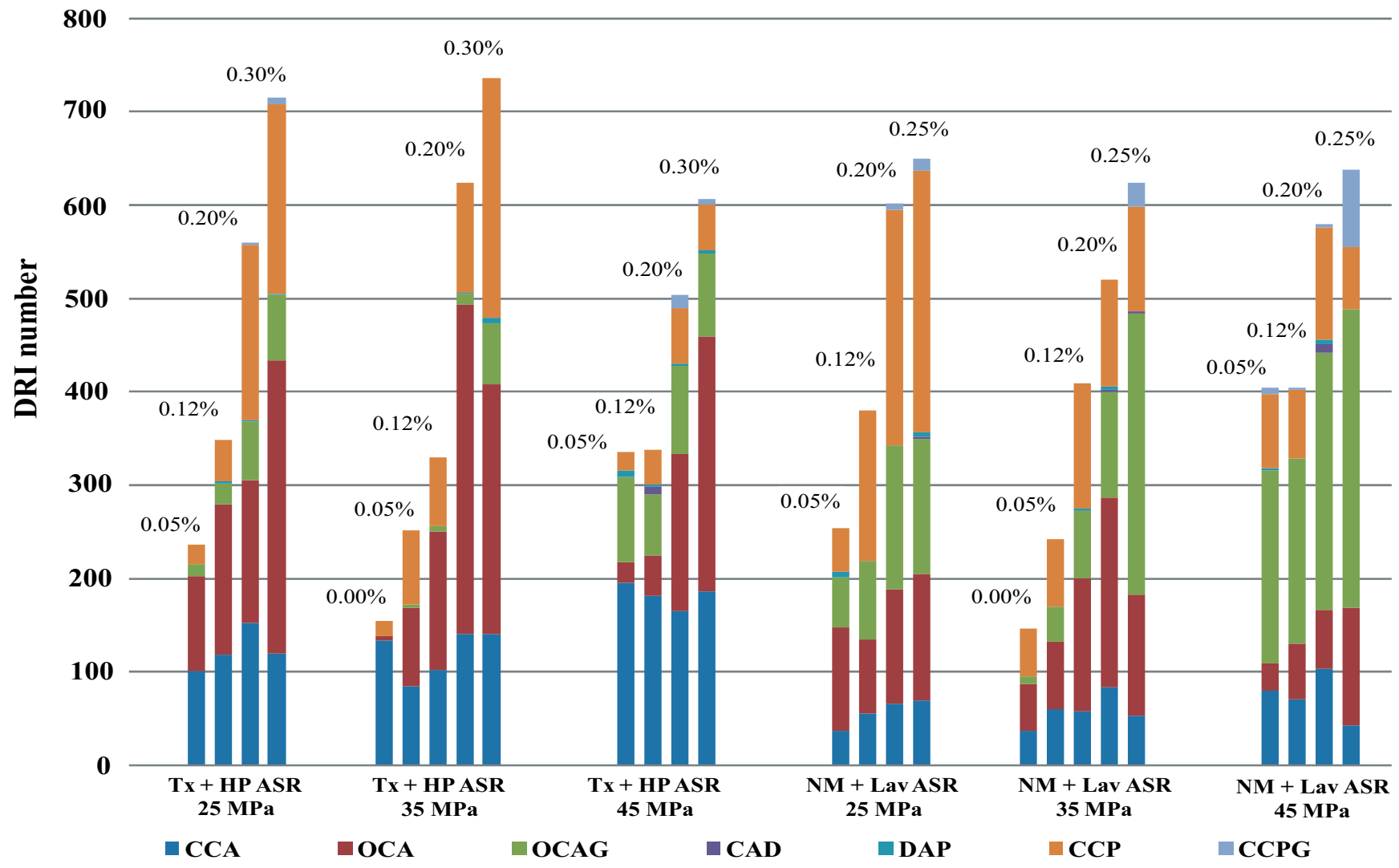

Figure 6

DRI charts for all the mixtures analyzed over the study. The common legend for all graphs is given in Figure $4 \mathrm{C}$

of AAR, whatever is the reactive aggregate type (fine vs. coarse) and concrete strength $(25,35$ and $45 \mathrm{MPa})$, as illustrated in Figure 6. Overall, two interesting distress patterns can be seen as a function of ASR expansion: 1) all the mixtures showed the presence of Closed cracks within the aggregate particles (CCA - blue sections), which is likely due to weathering of the aggregates and crushing procedures as proposed by Sanchez et al. [4]. This feature was even more evident in Tx mixtures, mainly in the non-reactive HP coarse aggregate particles, since HP is a limestone and presents both lower stiffness and hardness compared to NM aggregate. However, even though these features are not truly distress signatures, they still should be counted as they represent "fragile" sites of the aggregates particles which would be likely used as "fast tracks" for either the alkalis penetration or even distress development [4]; 2) while ASR progresses, the affected specimens showed to increase both their number of Opened cracks within the aggregate particles (with and without gel) and the Cracks in the cement paste (with and without gel) as a function of their increasing expansion. However, as by to [4], in the beginning of ASR, the distress features are more likely found within the aggregate particles whereas for higher expansion levels (i.e. $\geq 0.20 \%$ ), the amount of cracks in the cement paste becomes quite important.

\subsection{SDT \& DRI coupling}

The output parameters of both SDT and DRI presented a good correlation towards the expansion level achieved by the distressed specimens affected by different damage mechanisms, which means that they both correlate well with each other. However, instead of just correlating data between the above tools, according to [10], it is necessary to really understand what each tool measures; the SDT provides an indication of the extent of inner cracking within a damaged material while the DRI (through its weighing factors) measures the characteristics and the progress/development (i.e. expansion level) of a given damage mechanism. Therefore, the mechanical and microscopic tools discussed throughout this paper present some complementary character and need to be used together for the full assessment of distress in concrete.

\section{Conclusions}

As part of this study, the reliability of the Stiffness Damage Test $(S D T)$ and Damage Rating Index (DRI) for assessing damage in 25, 35 and $45 \mathrm{MPa}$ AAR-affected concrete, incorporating fine and coarse reactive aggregates was appraised. The main conclusions from the above investigations are presented hereafter: 
both the Stiffness Damage Test (SDT) and the Damage Rating Index (DRI) were able to distinguish the progress of "damage" (i.e. cracking) as a function of expansion for test specimens affected by ASR coming either the reactive fine or coarse aggregate and presenting different compressive strengths $(25,35$ and $45 \mathrm{MPa}$ );

- the most common microscopic feature seen through ASR distress is the Opened cracks (with and without gel) in the reactive aggregate particles. As ASR progresses, and for higher expansion levels (i.e. $0.20 \%$ ) the presence of cracks in the cement paste becomes more important;

- the SDT, through its output parameters, measures the amount of inner cracking in distressed concrete. On the other hand, the DRI measures the characteristics and the progress/development (i.e. expansion level) of a damaged mechanism. Thus, they present a complementary character;

- finally, although the SDT and DRI have shown great potential in the condition assessment of laboratory specimens (i.e. unreinforced concrete samples cast in the laboratory and undergoing free expansion), the use of the above tools for assessing cores extracted from real structures is quite limited, and needs to be evaluated so that the tools could potentially become important engineering procedures.

\section{Acknowledgements}

The funding of this project was provided by a grant from the Quebec Department of Transportation, under the supervision of Mr. Alain Hovington and Mrs. Nadia Pouliot. The authors would like to thank Mr. René Malo and Mr. Mathieu Thomassin from "le Centre de Recherche sur les Infrastructures en Béton (CRIB)" at Laval University, as well as the undergraduate research assistants who helped with the manufacturing and testing of the test specimens used in this project. L. Sanchez benefited from a Vanier scholarship financed by NSERC (Natural Sciences and Engineering Research Council of Canada).

\section{References}

[1] Fournier, B.; Bérubé, A. 2000. Alkali-aggregate reaction in concrete: a review of basic concepts and engineering implications. Canadian Journal of Civil Engineering, 27 (2): 167-191.

[2] Sanchez, L.F.M.; Fournier, B.; Jolin M.; Bastien, J. 2014. Evaluation of the Stiffness Damage Test (SDT) as a tool for assessing damage in concrete due to ASR: test loading and output responses for concretes incorporating fine or coarse reactive aggregates. Cement and Concrete Research, 56: 213-229.

[3] Sanchez, L. F. M.; Fournier, B.; Jolin M.; Bastien, J. 2015. Evaluation of the Stiffness Damage Test (SDT) as a tool for assessing damage in concrete due to ASR: input parameters and variability of the test responses. Construction and Building Materials, 77: 20-32.

[4] Sanchez, L. F. M.; Fournier, B.; Jolin M.; Duchesne, J. 2015. Reliable quantification of AAR damage through assessment of the damage rating index (DRI). Cement and Concrete Research, $67: 74-92$.
[5] Crisp, T. M.; Waldron. P.; Wood. J. G. M. 1993. Development of a non-destructive test to quantity damage in deteriorated concrete. Magazine of Concrete Research, 45 (165): 247-256.

[6] Crisp, T. M.; Wood, J. G. M.; Norris, P. 1989. Towards quantification of microstructural damage in AAR deteriorated concrete. International Conference on Recent Developments on the Fracture of Concrete and Rock. The University of Wales, Cardiff, September 1989, 9p.

[7] Walsh. J. B. 1965. The effects of cracks on the uniaxial elastic compression of rocks. Journal of Geophysical Research, 70: $339-411$.

[8] Crouch. R. S. 1987. Specification for the determination of stiffness damage parameters from the low cyclic uniaxial compression of plain concrete cores. Revision A. Mott. Hay \& Anderson. Special Services Division. Internal Technical Note.

[9] Smaoui. N.; Bérubé. M.A.; Fournier. B.; Bissonnette. B.; Durand. B. 2004. Evaluation of the expansion attained to date by concrete affected by ASR - Part I: Experimental study. Canadian Journal of Civil Engineering, 31: 826-845.

[10] Sanchez, L. F. M. 2014. Contribution to the assessment of damage in aging concrete infrastructures affected by alkaliaggregate reaction. PhD thesis, Laval University, Department of Geology and Geological Engineering, Quebec, Canada.

[11] Villeneuve, V.; Fournier, B.; Duchesne, J. 2012. Determination of the damage in concrete affected by ASR - The Damage Rating Index (DRI). 14th International Conference on Alkali-Aggregate Reaction (ICAAR). Austin, Texas (USA), May 2012.

[12] Powers, L.; Shrimer, F. H. 2009. Quantification of ASR in concrete: An introduction to the Damage Rating Index. ICMA conference. International Cement Microscopy Association/ Society of Concrete Petrographers joint meeting, Quebec City, Canada, May 2009.

[13] Grattan-Bellew, P.E.; Mitchell, L.D. 2006. Quantitative petrographic analysis of concrete -The Damage Rating Index (DRI) method, a review. Proc. Marc-André Bérubé symposium on AAR in concrete, CANMET/ACI Advances in concrete technology seminar, Montréal, Canada, May 31 \& June 1, 2006.

[14] Sanchez, L. F. M.; Multon. S.; Sellier, A.; Cyr, M.; Fournier, B., Jolin M. 2014. Comparative study of a chemo-mechanical modeling for alkali silica reaction with experimental evidences. Construction and Building Materials, 72 : 301-315. 